\title{
DO CAMPO ÀS PRANCHAS: EXPERIMENTAÇÃO DE MONTAGEM COM FOTOGRAFIAS VERNACULARES
}

\author{
Bianca de Camargo Setti ${ }^{1}$
}

\section{Introdução}

A fotografia, dentre suas diversas funções e potencialidades, é capaz de capturar e registrar os momentos da vida de uma pessoa e de seu entorno, do que ela presencia e observa. Atualmente, com o contínuo avanço das tecnologias fotográficas e do compartilhamento de imagens nas redes sociais, a prática fotográfica se torna ainda mais onipresente no cotidiano de grande parte da população mundial. O foco deste trabalho, entretanto, encontra-se na observação das fotografias vernaculares analógicas, imagens tornadas objeto, que são guardadas em gavetas, armários e, principalmente, nos álbuns familiares. Considerados arquivos por Silva (2008) e Samain (2012), os álbuns tocam nos âmbitos mais profundos da vida, nos imaginários em torno da família, de sua organização e sobre ela mesma.

De acordo com Santos (2015:37), a fotografia surge como uma nova forma de produzir memória e de adorar as imagens. Ainda segundo a autora, as fotografias vernaculares, que capturam a vida cotidiana, familiar, tem o poder de falar do homem mesmo, de suas relações com o outro, com o tempo e com a memória. Os álbuns, possivelmente o suporte mais comum deste tipo de fotografia, instaurariam uma temporalidade outra do que essa linear e evolutiva com a qual estamos habituados: "o tempo do álbum" é permeado pela oralidade, pela memória e pela narrativa (Santos, 2015:95). Dessa forma, fixando um instante, mas não o relato sobre ele, cada família possui a chance de fabricar suas próprias memórias através das fotografias dos álbuns.

O presente trabalho foi desenvolvido, inicialmente, para a disciplina "Arquivo, Imagem e Antropologia" (IFCH-Unicamp), ministrada por Fabiana Bruno no segundo semestre de 2019, e tem como objetivo estabelecer um diálogo entre a experiência da

\footnotetext{
${ }^{1}$ Universidade Estadual de Campinas, Brasil. Email: bii.cam.setti@gmail.com ORCID id : https://orcid.org/0000-0001-9604-0039
} 
pesquisa de campo realizada em minha Iniciação Científica ${ }^{2}$ e a literatura discutida na disciplina, assim como a execução de uma experimentação que abordou os processos de construção de um pensamento por imagens. O trabalho se dividirá, portanto, em três momentos.

Em um primeiro momento, discorrerei sobre a viagem de campo realizada para minha pesquisa de Iniciação Científica em General Salgado, pequeno município do interior de São Paulo, na qual tive a oportunidade de percorrer os álbuns fotográficos de I., (63), mãe, avó, irmã, crescida no sítio de sua família com suas seis irmãs e, atualmente, residente da área urbana da cidade perto de uma parte da família e distante da outra que acabou se deslocando para regiões mais próximas à capital. Abordarei a experiência de campo à luz das teorias de Felizardo e Samain (2007), Santos (2015) e Silva (2008) sobre álbuns familiares, fotografia e memória.

Em um segundo momento, falarei sobre a experiência de montagem inspirada nas pranchas do Atlas Mnemosyne de Aby Warburg e na compreensão do processo de montagem como forma de produção de conhecimento, na qual movimentei algumas fotografias dos álbuns de I., re-fotografadas por mim, para um fundo preto. Mobilizarei alguns estudiosos de Warburg como Didi-Huberman (2013; 2015; 2018), Checa (2010) e Calderón (2017) em uma breve apresentação sobre o próprio Aby Warburg e seu Atlas Mnemosyne, assim como alguns conceitos de Bruno (2003), na busca por compreender os processos envolvidos na montagem da minha prancha.

Finalmente, em um último momento, procurarei perceber de que maneira a montagem da prancha modifica a relação entre imagem e observador, assim como as relações entre as próprias imagens, a partir das noções de intervalo e memória para Warburg, dialogando com o que foi discutido nos dois primeiros tópicos do trabalho, novamente, a partir de seus estudiosos e ainda, Cunha (2004), Samain (2012) e Sierek (2009).

\section{A experiência em campo}

Álbuns fotográficos familiares me fascinam desde cedo, quando juntas, eu e minha avó passávamos tardes percorrendo um por um. Escolhê-los como objeto de estudo se mostra uma experiência incrível, afinal trato de algo que faz parte de quem eu

\footnotetext{
2"Sobre os estatutos da prática da fotografia do post mortem no século XXI", fomentada pelo PIBIC/CNPq, sob a orientação da Professora Dra. Suely Kofes e coorientação da pesquisadora Dra. Fabiana Bruno.
} 
sou e que me provoca inquietações e questionamentos. Realizar a primeira pesquisa de campo, olhar os álbuns e ouvir sobre as fotografias neles contidas, apesar de animador, acabou por se tornar, ao longo da experiência, um pouco desafiador diante da imensidão de imagens com as quais estava prestes a lidar. Como selecionar o que registrar? Quais fotografias re-fotografar?

Tais questões começaram a surgir assim que Dona I. ${ }^{3}$ levou até a sala de estar de sua casa, localizada no pequeno município de General Salgado-SP, uma gaveta de guarda-roupas cheia de álbuns $10 \mathrm{~cm} \times 15 \mathrm{~cm}$. Para ser mais exata, cheia dos seus 36 álbuns. A princípio imaginei que não iríamos percorrer todos eles. Afinal de contas, pedi que me mostrasse e comentasse apenas sobre as fotografias e os álbuns que desejasse. Ainda assim, percebi grande preocupação por parte da interlocutora em percorrer todos eles e fornecer a maior quantidade de detalhes sobre cada um.

Sua preocupação, no entanto, não é de se espantar. Se retomarmos Leite (1993), a autora nos diz que "as fotografias de família possuem um teor ritual de culto doméstico, satisfazendo a necessidade de fixar e reproduzir uma experiência, além de agir como protetora contra a ação do tempo, substituindo de forma mágica o que o tempo destruiu." Podemos imaginar, assim sendo, que ao realizar o movimento de observar as fotografias e narrar sobre elas, aquela que o faz encontra uma maneira de retornar às lembranças já esquecidas, recobrar memórias que tendem a surgir, principalmente, quando olhamos para a fotografia.

Para Samain:

As fotografias são tecidos, malhas de silêncios e ruídos. Precisam de nós para que sejam desdobrados seus segredos. As fotografias são memórias, histórias escritas nelas, sobre elas, de dentro delas, com elas. É por essa razão, ainda, que as fotografias se acumulam como tesouros, dentro de pastas, de caixinhas (...). Elas são nossos pequenos refúgios, os envelopes que guardam nossos segredos. As pequenas peles, as películas, de nossa existência. As fotografias são confidências, memórias, arquivos. (Samain, 2012:160)

Fotografia e memória confundem-se. Uma está contida na outra e ambas carregam traços de credibilidade por evidenciar as coisas como se parecem e por mostrar os caminhos da lembrança (Felizardo e Samain, 2007). A fotografia - enquanto

\footnotetext{
${ }^{3}$ Em concordância com as normas do comitê de ética em pesquisa, utilizarei somente as iniciais dos nomes das pessoas envolvidas neste trabalho (e na pesquisa por trás dele) buscando preservar suas identidades.
} 
uma "memória voluntária" - talvez se coloque como a forma mais precisa, rápida e moderna de perpetuá-la, além de resgatar a lembrança, o processo de rememoração, através dos seus ícones, índices e símbolos 5 .

A maneira como I. abordava cada imagem variava em níveis de profundidade. A algumas fotografias só lhes eram designadas a preocupação em identificar datas, locais e pessoas - quase como se estivesse realizando um processo de catalogação -, enquanto outras recebiam uma atenção especial: I. me contava sobre o que estava representado, qual era a relação entre as pessoas nelas retratadas, quais estavam vivas e quais já haviam morrido, por exemplo. Raramente passava por uma foto sem fazer comentários sobre ela. A metáfora da "reconhecença", noção apresentada e discutida na tese de mestrado de Bruno (2003), pode nos ajudar a pensar no motivo de algumas fotografias acabarem sendo mais privilegiadas sob o olhar e a fala de I.

Segundo a autora, reconhecença é um termo pertencente ao vocabulário dos marinheiros e designa, de forma simplificada, um pedaço de terra que permite ao navegante saber em qual parte do litoral ele se encontra (Bruno, 2003:74). No horizonte de imagens dentro dos diversos álbuns, algumas se avultam aos olhos da minha interlocutora e guiam o caminho pelo qual ela passa a percorrê-las. $\mathrm{O}$ afeto desempenha um importante papel alimentando o processo de escolha, pois algumas fotografias evocam memórias mais potentes, proporcionando um diálogo muito maior e mais detalhado com a pessoa que as observa. De acordo com Santos (2015), a fotografia de alguém $^{6}$ por quem sentimos afeto não permanece no campo da representação, mas guarda algo de sua presença, convocando nossa memória e nosso corpo ao olharmos para ela. "O afeto provoca a magia da imagem: faz retornar qualquer coisa de perdido" (Santos, 2015:30).

Pude perceber então - e isso ocorreu após olhar as imagens que capturei enquanto I. me mostrava seus álbuns e falava sobre eles - que acabei me atentando justamente a essas fotografias que evocavam memórias mais profundas e, no caso dela, estavam relacionadas à família, aos amigos e aos espaços nos quais os laços foram sendo constituídos. Além disso, a partir de alguns comentários, torna-se possível notar a

\footnotetext{
${ }^{4}$ É importante ressaltar que a fotografia, de acordo com Felizardo e Samain (2007), deve ser considerada uma memória voluntária, não espontânea, que repete o passado ao invés de representá-lo, como um hábito corriqueiro e superficial. Uma lembrança "controlada".

${ }^{5}$ Ibid., p.212.

${ }^{6}$ Acredito que não só de alguém, mas também de algo.
} 
sua preocupação diante da possibilidade de perder tais memórias e não conseguir transmiti-las para as próximas gerações:

Ai, saudade né. As fotos a gente vê e dá saudade (...). Se a gente não tinha tirado essas fotos, não tinha recordação né. Tipo assim, igual as crianças, não ia ver essas coisas, conhecer lá o sítio que a gente vai. (I., 2019) ${ }^{7}$

Por mais que o sítio ainda exista, passado por algumas reformas e com novos moradores, o que importa, de acordo com I., para além de possuir a fotografia do local, é poder rememorar e transmitir o que está inculcado à sua imagem, às lembranças do período em que lá habitou, suas experiências e relações construídas no lugar.

Silva (2008) explica que o ato de arquivar remonta ao desejo de manter a memória viva, ao medo do esquecimento e da destruição. Posto isto, de acordo com o debate proposto pelo autor e também a de partir Samain (2012), torna-se possível pensar nos álbuns familiares como arquivos. Arquivos estes que, dentro do seu funcionamento temporal característico, possuem a capacidade de abolir tempo, hierarquia e distância, como aponta Santos (2015). Quando refletimos sobre a não linearidade temporal e a ausência do caráter cronológico dos álbuns acusados pela autora, notamos estar diante de um tipo de arquivo que possibilita, por exemplo, reviver os mortos e estar, ao mesmo tempo, diante do presente e do passado a partir do olhar e da fala, da memória e da narrativa que dela se constrói.

\section{Movimentando as imagens}

Aby Warburg (1866-1929), pesquisador alemão, dedicou-se entre o final do século XIX e o início do século XX a repensar a disciplina da história da arte, propondo sua reconfiguração a partir da transversalidade de diversas disciplinas como história, antropologia, psicologia, filosofia, arte e estética, caminhando em direção a uma “ciência da cultura" (Maciel, 2018). Seu último trabalho, o Atlas Mnemosyne, pode ser considerado a culminância do esforço de Warburg na busca por um modo de conhecimento "cujos argumentos são formulados e desenvolvidos pelas próprias imagens quando relacionadas, visando promover a ativação das forças nelas contidas" 8 .

\footnotetext{
${ }^{7}$ C.,I. Entrevista concedida a Bianca Setti. General Salgado, 15 dez. 2019 [Somente iniciais do sobrenome e nome devido ao protocolo de sigilo exigido pelo Comitê de Ética em Pesquisa].
}

${ }^{8}$ Ibid., p.192. 
Projeto iniciado em 1924 e não finalizado devido à morte do pesquisador, o Atlas Mnemosyne é composto por 63 pranchas $^{9}$ e 971 imagens. As reproduções fotográficas dessas imagens eram fixadas em painéis de tecido preto com pinças, “estandartes monocromáticos de fragmentos visuais, [uma] analogia ao fundo negro e abissal da memória ${ }^{10}$ ". O material é organizado em grupos e séries de acordo com nexos que sugerem diferentes relações visuais, geográficas e históricas. (Calderón, 2017)

\begin{abstract}
Os painéis que compõem o Atlas consistem em um conjunto de imagens organizadas por meio de relações visuais definidas por certos motivos recorrentes superviventes - de temas, gestos e expressões corporais, onde se pode encontrar o material de uma heterogeneidade de fontes não consideradas habitualmente pelos historiadores da arte. (Calderón, 2017:55) ${ }^{11}$
\end{abstract}

Mnemosyne, segundo Checa (2010:139) “quer ser, portanto, um atlas visual no qual através de considerações comparativas, se mostra um inventário dos precedentes antigos conservados na memória" 12 , através do "espaço respiratório" que pode ser percebido visualmente nos intervalos representados pelo fundo preto - suporte descontínuo devido aos hiatos produzidos pelas imagens nele fixadas e, ao mesmo tempo, sendo aquilo que as une.

A noção de intervalo refere-se à distância entre sujeito e objeto, que deve ser estabelecida para uma melhor compreensão daquilo que é observado, podendo ser considerado como um "espaço para a reflexão". O que possibilita essa distância entre uma coisa e outra, ou seja, o espaço entre, o intervalo e, dessa forma, sua observação atenta e profunda, é a memória (mnemosyne) (Calderón, 2017:26). A memória que conserva as recordações não funciona de maneira sucessiva, mas estratificada. Dessa forma, as recordações e as memórias podem intensificar-se através da observação atenta - relação entre observador e imagem -, das trocas entre elas mesmas, e não somente serem produzidas através das reminiscências de temas, traços e assuntos semelhantes (Checa, 2010).

Para Warburg, o princípio de montagem aparece então como um modo de colocar em justaposição as imagens para restituir suas cargas elétricas através das relações que surgem entre elas, colocando em cena suas possibilidades de significação ou de sentido ${ }^{13}$ (Calderón, 2017: 54).

\footnotetext{
${ }^{9}$ Deveriam ser 79 pranchas no total.

${ }^{10}$ Ibid., p. 192 .

${ }^{11}$ Tradução minha.

${ }^{12}$ Tradução minha.

${ }^{13}$ Tradução minha.
} 
De acordo com Didi-Huberman (2015), a desmontagem do visível, nesse caso a reconstrução de um pensamento inicialmente linear em um anacrônico, só possui sentido quando reconfigurado e retrabalhado visualmente. Em outras palavras, só adquire sentido na montagem do material obtido. Mais do que simplesmente recolocar tais imagens produzidas em um fundo preto, o processo de montagem deve ser considerado, portanto, como método, como forma de produção de conhecimento ${ }^{14}$.

Para Warburg, segundo Didi-Huberman (2013), as imagens constroem-se a partir da relação entre aquele que observa e aquilo que é observado ${ }^{15}$, sendo capazes de dizer algo sobre os observadores mesmos. Dessa forma, por meio das narrativas da interlocutora e da operação de contemplação de suas fotografias (Bruno, 2003:81), fui guiada por motivações afetivas, da mesma forma como I. foi guiada diante de seu oceano de imagens.

Todavia, é importante ressaltar que o que ocorre com relação aos afetos da interlocutora é uma compreensão da minha parte, e não um compartilhamento necessariamente. $\mathrm{Eu}$ compreendo seus sentimentos e emoções ao olhar para as fotografias como alguém que também nutre um apreço pelas fotografias vernaculares, o que implica um novo processo de "reconhecença" feito por mim, que se dá de forma diferente do dela. Para além da ordem sentimental, entretanto, o afeto surge também como a capacidade de afetar - as imagens afetam $\mathrm{I}^{16}$., sua narrativa me afeta e, dessa maneira, meu olhar é afetado ao fotografar suas fotografias e lidar com elas posteriormente. O afeto em sua dupla dimensão apresenta-se como potência de transformação, de movimento.

"Frente ao objecto o sujeito olha e é olhado, expõe-se e é exposto. O objecto não se apresenta como uma peça monolítica com ênfase num interior/exterior formais, mas sim como uma entidade fracturável (e fracturante) na qual se rasgam abertura improváveis por onde se precipita o olhar em desassossego" (Almeida, 2012:309).

O processo de re-fotografar algumas de suas fotografias e, posteriormente, realizar uma nova seleção, permeado por um embate, um conflito de afetos, acaba por desmontar o caminho seguido pela narrativa e memória da interlocutora devido aos intervalos surgidos - e aqui amplio a noção de intervalo mencionada em parágrafos

\footnotetext{
${ }^{14}$ Ibid., p. 132.

${ }^{15}$ Ibid., p. 34.

${ }^{16}$ De acordo com Samain (2012), as imagens desejam ser contempladas, nos inquietam esperando que façamos a experiência do que significa ser imagem.
} 
anteriores - no ato de "receber" uma imagem a partir de uma multidão de afetos em processos.

Considerando que Didi-Huberman (2015) aponta a montagem, a reconfiguração, como aquilo que produz sentido ao movimento de desmontagem, como visto anteriormente, e procurando colocar em prática a atividade de experimentação proposta pela professora Fabiana Bruno para o fechamento da disciplina "Arquivo, Imagem e Antropologia" (IFCH-Unicamp, 2019), decidi operar com a montagem uma prancha com as "re-fotografias" selecionadas por mim, inspirada no trabalho do próprio Aby Warburg em seu Atlas Mnemosyne.

Sete fotografias foram selecionadas e colocadas sobre um fundo preto. Compreender a "reconhecença" como uma metáfora para pensar o trabalho da memória é importante, pois refere-se a uma etapa anterior à da escolha e da montagem, também alimentadas por motivações afetivas, pela capacidade de sermos afetados por aquilo que olhamos. O processo de montagem, de acordo com Bruno (2003), caminha muito próximo ao da triagem, estando o princípio de organização sempre vinculado à escolha, apesar de, à primeira vista, parecer algo aleatório e desorganizado.

As fotografias selecionadas por mim poderiam ser divididas em três "temas" dentre os apresentados nas falas de I.: "família", "tio P." e "Sítio". As imagens 3 e 4 na prancha, especificamente, me saltaram aos olhos, também pelo caráter estético. São paisagens lindas e, de alguma maneira, nostálgicas, apesar de nunca ter estado nos lugares representados. 
Prancha 1

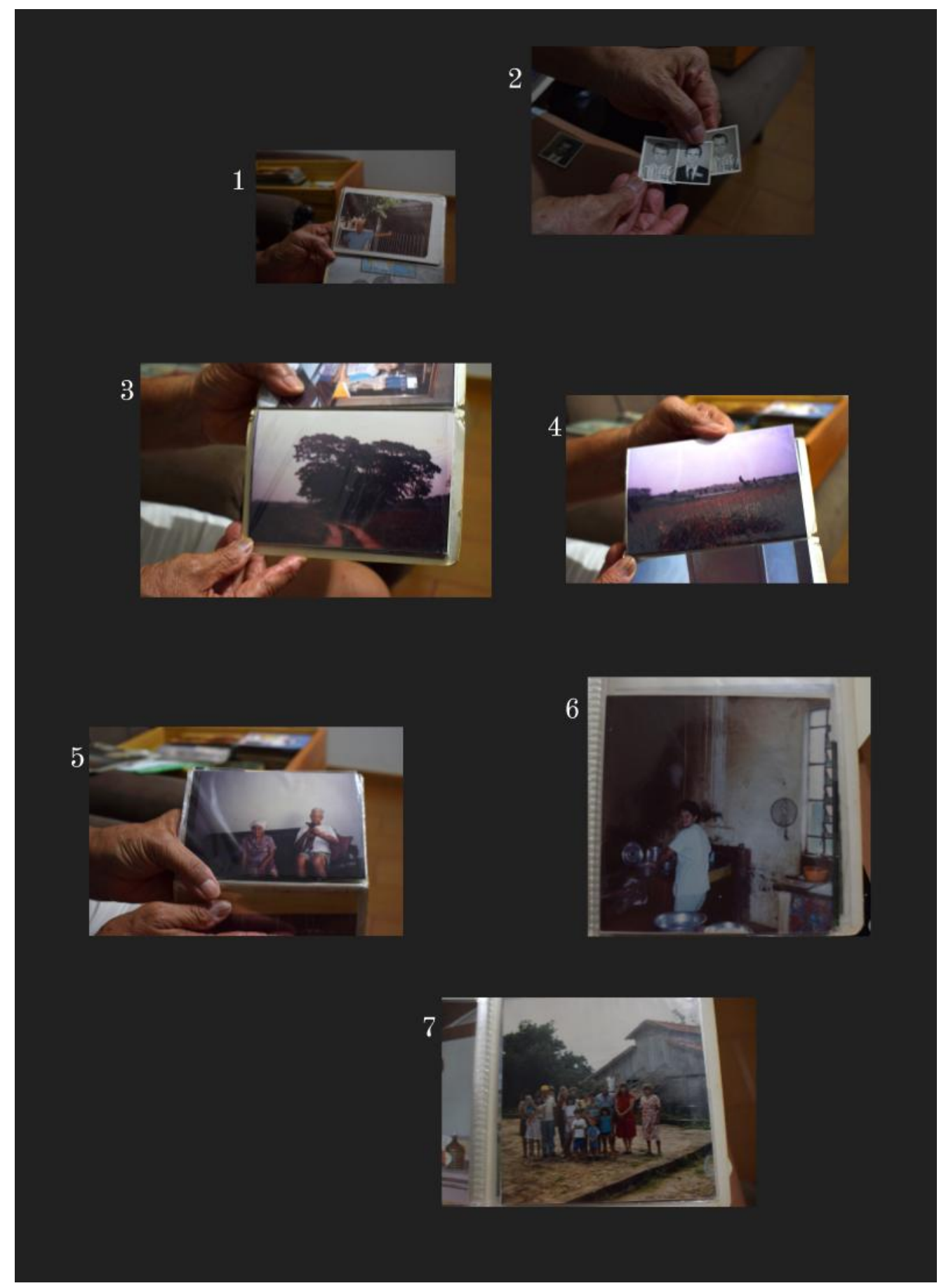

1. Tio $\mathrm{P}$.

2. Fotos $3 \times 4$ do Tio P.

3. Caminho para o sítio.

4. Plantação para dar aos animais.

5. Titia, Tio P. e o cachorro dele.

6. Cozinha.

7. Sítio. 


\section{Montagem e prancha}

A partir do que já foi apresentado no presente trabalho, proponho a aproximação entre alguns pontos do primeiro e do segundo tópico para possíveis reflexões. Tomando como base Didi-Huberman (2015; 2018), Calderón (2017) e Checa (2010), consideramos o Atlas Mnemosyne um espaço analítico, local de uma operação que atua de formas distintas nas relações estabelecidas com as imagens e entre elas. A teoria da memória de Warburg se organizou inteiramente a partir da noção operatória de intervalo, dizendo respeito a uma técnica de visualização que não pode ser considerada narrativa, explicativa, contemplativa ou muda (Didi-Huberman, 2018:277).

É certo que a teoria Warburguiana balançou as estruturas da história da arte e da própria disciplina de história, gerando problemáticas epistemológicas ao propor um modelo anacrônico de produção de conhecimento e análise. Seu objetivo não era esclarecer a história da arte. De acordo com Didi-Huberman (2018), Warburg buscava torná-la mais complexa, obscurecê-la, propondo “(...) uma cartografia em camadas da memória, a partir de conjuntos de imagens que rompiam fronteiras geográficas e temporais" 17 .

Poderíamos, então, considerar os álbuns familiares como um modelo canônico e determinista do próprio processo de conhecimento? Acredito não ser possível afirmar que todas as pessoas organizem fotografias vernaculares de forma linear, retratando suas histórias familiares de maneira cronológica, acontecimento por acontecimento, desde o início de suas formações até a morte daqueles que as iniciaram. Ora, seria até difícil pensar assim, pois estaríamos desconsiderando todas as possíveis ramificações de uma estrutura familiar e os caminhos seguidos por aqueles que a compõem. Também não acredito, por outro lado, ser muito comum encontrar fotografias distribuídas aleatoriamente nos álbuns. No caso de I., muitos dos seus álbuns possuíam na capa uma breve descrição do que poderia ser encontrado ali: “Casamento de E. e R. 21/07/1997”; “Segundo E.T.E I. 'O encontro' Novo Horizonte Interact Club.” e “Fotos do sítio”, por exemplo

Referente aos álbuns vistos em campo, por conseguinte, não podemos considerálos como um "depósito desorganizado" como coloca Silva (2008:44) ao referir-se às fotografias "soltas" - guardadas de forma aleatória, sem qualquer tipo de ordenamento.

\footnotetext{
${ }^{17}$ Ibid., p. 247.
} 
É possível que entre um álbum e outro dentro da gaveta exista a possibilidade de grandes disparidades com relação aos temas, acontecimentos e etc. Mas, dentro de cada um deles, as imagens não estavam distribuídas de forma totalmente aleatória. Havia uma classificação - ainda que mínima - relacionada principalmente a ritos, acontecimentos e datas especiais. Podemos, portanto, pensar na noção de arquivo para estas imagens também a partir de Cunha (1997), que o compreende como sendo “(...) técnicas de ordenamento e controle de tudo aquilo que, de outra forma, estaria virtualmente sujeito ao desaparecimento e à dispersão”. (Cunha, 1997: 292)

Contudo, como visto no primeiro tópico do presente trabalho, Santos (2015) aponta um funcionamento temporal característico dos álbuns, capaz de romper com linearidades e fronteiras. Tal caráter anacrônico talvez possa ser mais bem compreendido a partir de Samain (2012), que considera o arquivo como memória em latência, que cochila e pode ser descoberta, reaberta. Entretanto, não deve ser visto como algo pertencente somente ao passado, mas sim uma coleção de unidades vivas, enclausuradas e, no entanto, sempre em movimento, buscando reconstrução e recomeço. Os arquivos devem ser encarados, portanto, como inquietações e questões para pensar, interrogar nosso presente, não como meras lembranças, e sim memórias que não morrem, mas que se inquietam e viajam. "As memórias de arquivos são sempre questões postas diante de nossa história, interrogações que olham para nós." (Samain, 2012:160, 161).

O autor explica que, muito mais do que objetos, enquanto lugares de processos vivos, as imagens participam de um sistema de pensamento, porém o que elas nos mostram nunca será um pensamento único e definitivo, mas sim um caminho em direção a outras profundidades e estratificações. O tempo das imagens é outro, é anacrônico, e por isso nunca as esgotamos, "não conhecemos nem as origens, nem as andanças, nem os destinos" (Samain, 2012:159). Se as imagens compreendidas como arquivos familiares, as fotografias vernaculares e os álbuns, são dotadas de tal potência, o que o processo de montagem da prancha tem a nos dizer? Ou melhor, a nos mostrar?

Para Sierek (2009) o processo de montagem demonstra a intenção das imagens para a dinamização. As fotografias, nesse caso, assim como não se limitam ao visível, à figuração somente, não se limitam também a si mesmas, buscando estabelecer movimentos em direção às outras. O movimento das imagens, sua energia cinética, faz com que atuem como um tipo de "interruptor" entre passado e presente de forma a 
impulsionar a memória. O que coloca essas imagens em movimento, portanto, é a comparação, ainda de acordo com o autor. É no ato de colocar uma coisa em relação à outra que deixamos com que os nossos olhares as percorram, possibilitando que nós mesmos nos coloquemos em movimento, ao relativizar nossas próprias posições com relação a elas.

É também no ato associativo que percebemos as polaridades das imagens e as possibilidades de se relacionarem de diferentes formas, com tantas outras, sob cada novo olhar. Resultado da desmontagem do caminho seguido por I., em seus álbuns e sua narrativa, olhamos para as fotografias sobre a prancha e encontramos inúmeros outros caminhos de memórias e afetos. As operações que permeiam o processo de montagem, desde a "re-fotografia", a seleção e a prancha em si, assim como os intervalos entre as imagens na prancha, visualmente marcados pelo fundo preto - noção de intervalo mais aproximada à de Warburg, debatida por seus estudiosos - facilitam as correspondências entre as imagens e a percepção das relações estabelecidas entre elas, mostrando muito mais do que eu - e possivelmente a própria interlocutora - acreditava estar vendo.

Não existe um único caminho a ser seguido quando estamos diante da prancha, diferente do que ocorre com os álbuns ${ }^{18}$, geralmente vistos da esquerda para a direita. A prancha nos permite percorrer diversas direções partindo de cada imagem. Podemos percorrê-la de forma cíclica, variando por qual foto iniciar o trajeto; podemos percorrêla também de cima para baixo, de baixo para cima, da esquerda para a direita cruzando diagonais entre elas, conforme sugere Bruno (2009) quando debate a montagem de fotobiografias. Podemos iniciar o olhar na primeira fotografia do canto superior esquerdo, indo para a terceira do lado direito de cima para baixo e depois para a que está acima dela. Em suma, realizo também esses trajetos imaginários entre as imagens com o intuito de auxiliar a percepção da infinidade de vias a serem tomadas, que se desprendem do álbum e da narrativa que, inclusive, inicialmente, guiaram o meu processo de seleção e montagem.

O que significa a fotografia do caminho? O que ela tem a ver com o Tio P. e com a Titia? Como elas dialogam com a própria I., mais jovem, cozinhando, e com a clássica foto da família reunida? Movimentar as imagens do álbum para a prancha, suporte outro, estabelece uma relação distinta com a memória, não significa destruir as

\footnotetext{
${ }^{18}$ Principalmente os $10 \times 15$ observados em campo, nos quais cada plástico acomoda duas fotografias com seus versos virados uma para outra.
} 
conexões entre as imagens ou realizar um movimento sem objetivo, dotado somente de caráter estético. Significa conceber uma nova relação com as imagens e entre elas, possibilitando a capacidade de suscitar comparações, valendo "por sua maneira de descobrir e de construir todo um mundo de afinidades ou de conflitos até então desconhecidos" (Didi-Huberman, 2018:281).

As memórias surgem em diversas direções. Se inicialmente acreditei, a partir do resultado de minha montagem, que meu objetivo tinha sido o de mostrar as memórias relacionadas ao caminho até a antiga casa de I., onde lá estavam sua família e amigos próximos, a importância desse espaço e de seus tios na construção de sua família e de si mesma, pude perceber depois o que não estava tão claro tendo como base somente os álbuns e a narrativa, assim como uma observação superficial da prancha. $\mathrm{O}$ caminho para sua casa é memória feliz e também triste, há a nostalgia de ter começado sua família por lá e há também as dificuldades em trabalhar na roça para seus antigos patrões. Olhar para a família e amigos reunidos retoma o prazer da união, mas também a dor da perda de todos os que já partiram ou se ausentaram de alguma forma. Aqui a morte surge em meio aos vivos.

O processo de montagem das fotografias em uma prancha, o ato de colocar as imagens em relação, de visualizá-las de forma diferenciada entre os intervalos proporcionados pelo fundo preto, que atua como espaço de condutibilidade entre elas, promove uma percepção mais sutil e, ao mesmo tempo, complexa, das conexões entre os diferentes tempos das fotografias. Aponta de forma intensificada os anacronismos dessas imagens e as possibilidades de relações a serem estabelecidas, desestruturando a narrativa de I., e promovendo o movimento de uma imagem à outra através dos intervalos. "Suas diferenças se animam, suas analogias e seus contrastes descrevem um tipo de metamorfose ofegante, de acordo com um movimento que nunca é contínuo" (Didi-Huberman, 2015:155).

Deste modo, a memória se expõe não como uma sucessão de eventos concatenados causalmente, mas como impressões visuais organizadas em cadeias seriais segundo afinidades morfológicas e significantes. Não é um prontuário de imagens que prestam apoio visual ao que se diz com palavras, mas a exposição da memória em ação, em outras palavras, a memória viva e em movimento. (Calderón, 2017:57) 


\section{Considerações finais}

Este trabalho teve como objetivo fazer dialogar parte da minha pesquisa de Iniciação Científica, especificamente a discussão sobre fotografias vernaculares e álbuns familiares, com as reflexões teóricas trazidas na disciplina Arquivo, Imagem e Antropologia (IFCH-Unicamp), ministrada por Fabiana Bruno, assim como a realização de uma experimentação com montagem de pranchas, buscando refletir em torno da potência de produção de conhecimento e do pensamento por imagens. Para tanto, inspirada no Atlas Mnemosyne, de Aby Warburg, e nos debates realizados por alguns de seus estudiosos - estudiosos da imagem - realizei a montagem de uma prancha com fotografias produzidas durante minha viagem de campo.

A partir do breve relato da pesquisa de campo em General Salgado-SP, na qual tive a oportunidade de acompanhar I. percorrendo seus diversos álbuns, foi possível perceber a importância da fotografia enquanto memória e o caráter de relíquia que elas adquirem. Podendo ser vistas como lugares de afeto, são constituídas na relação entre elas e aqueles que as observam, tratando não somente do passado, mas transitando entre as diversas temporalidades das imagens. São lugares de processos vivos nunca esgotáveis.

A experiência de uma operação de montagem e de combinação de imagens foi motivada por esses conflitos de afetos e então desencadeada ao visualizar os álbuns de I., a partir de meus próprios afetos. Compreendo-os, mesmo sem compartilhar, necessariamente, os mesmos afetos que minha interlocutora naquele momento. Fotografar suas fotografias, portanto, se torna um processo de seleção que desmonta a narrativa e o caminho percorrido pela interlocutora. Instigada pelo que foi dito, me apoiando na noção de intervalo e no entendimento de que a montagem se trata de uma forma de produção de conhecimento, reorganizei as "re-fotografias" sob o fundo preto, em contraste com ele, dando origem a uma prancha.

As potencialidades das fotografias podem ser notadas, conforme a discussão realizada, independente do suporte nas quais se encontram. Todavia, os intervalos visualizados como o fundo preto entre as imagens, a comparação e as relações estabelecidas entre elas na prancha, me parecem facilitar a percepção de uma descontinuidade da memória, que se intensifica entre os movimentos de uma imagem à outra, entre os movimentos do nosso próprio olhar. Em um direcionamento de 
aproximação com os estudos das imagens e de algumas noções de Warburg, em um esforço experimental, arrisco dizer, que o processo de montagem da prancha evidenciou as potencialidades das imagens no seu tratamento sobre nós mesmos, nossos afetos e lembranças.

\section{REFERÊNCIAS}

ALMEIDA, Cristina Vasconcelos de. Recensão: Georges Didi-Huberman," O que nós vemos, o que nos olha". Revista de História da Arte, n. ${ }^{\circ} 10$ (2012), v. 10, p. 309-311, 2012.

BRUNO, Fabiana. Retratos da velhice - um duplo percurso: metodologico e cognitivo. Dissertação (mestrado) - Universidade Estadual de Campinas, Instituto de Artes, Campinas, SP, 2003.

BRUNO, Fabiana. Fotobiografia. Por uma Metodologia da Estética em Antropologia. 2009. 351f. Tese (Doutorado em Multimeios) - Instituto de Artes, Universidade Estadual de Campinas, Campinas, 2009.

URUEÑA CALDERÓN, Juan Felipe. El montaje en Aby Warburg y en Walter Benjamin. Editorial Universidad del Rosario, 2017.

CHECA, Fernando. La idea de imagen artística en Aby Warburg: el Atlas Mnemosyne (1924-1929). Atlas Mnemosyne, p. 135-154, 2010.

CUNHA, Olívia Maria Gomes da. Tempo imperfeito: uma etnografia do arquivo, Mana, v. 10, n. 2, Rio de Janeiro, 2004.

DIDI-HUBERMAN, Georges. A imagem sobrevivente: história da arte e tempo dos fantasmas segundo Aby Warburg. Rio de Janeiro, Contraponto, 2013.

DIDI-HUBERMAN, Georges; ARBEX, Márcia; NOVA, Vera Casa. Atlas ou o Gaio Saber Inquieto-O Olho da História, III. Tradução de Márcia Arbex e Vera Casa Nova. Belo Horizonte, Editora UFMG, 2018.

DIDI-HUBERMAN, Georges. Diante do tempo: história da arte e anacronismo das imagens. Belo Horizonte: Editora UFMG, 2015.

FELIZARDO, Adair; SAMAIN, Etienne. A fotografia como objeto e recurso de memória. Discursos fotográficos, v. 3, n. 3, p. 205-220, 2007. 
MACIEL, Jane Cleide de Sousa. Atlas Mnemosyne e saber visual: atualidade de Aby Warburg diante das imagens, mídias e redes. Revista Ícone. Recife, Vol. 16, N. 2, 191209, UFPE, 2018.

SAMAIN, Etienne. As peles da fotografia: fenômeno, memória/arquivo, desejo. Visualidades, v. 10, n. 1, 2012

SANTOS, Carolina Junqueira dos. O corpo, a morte, a imagem: a invenção de uma presença nas fotografias memoriais e post-mortem. Tese (doutorado) - Universidade Federal de Minas Gerais, Escola de Belas Artes, Belo Horizonte, 2015.

SIEREK, Karl. Images oiseaux: Aby Warburg et la théorie des médias. Klincksieck, 2009.

SILVA, Armando. Álbum de família: a imagem de nós mesmos. Senac, 2008

Recebido: $10 / 02 / 2020$

Aprovado: 15/07/2020 